Integritas 3.3 (Spring 2014), pp. 19-21.

doi: $10.6017 /$ integritas.v3iзp19

\title{
Response to William C. Mattison III
}

\section{David Quigley}

I appreciated the ways in which Mattison's essay works in different registers, mixing the biographical with the scholarly, jumping from reflections on Aquinas to the messiness of contemporary curriculum revision. Bill provides us with a clarifiying exploration of his own work on the emotions and moral theology, and how he's drawn inspiration from both the social and natural sciences. In interesting ways, Bill's work complements John Cunningham's exploration of some areas of relative weakness among Catholic universities when it comes to the natural sciences. ${ }^{\mathrm{I}}$ Bill offers up, early on in his essay, the phrase "science done well" to suggest a kind of ideal we should be aiming for on our campuses. Reading his essay, and reflecting on my own experiences at Boston College, I'm afraid that we fall short of that mark too often. In terms of the kind of science experiences we offer most of our non-science-major students in the core curriculum, it would be a stretch to describe what often happens as "science done well." Science faculty are too often allowed to distance themselves from broader currents in our universities, a phenomenon that is understandable given the complexities inherent in running a funded laboratory in the current environment and the eternal pressures of chasing after the next grant. Yet something important is lost, and the limited scientific excellence on our campuses too often is separated off from much of the rest of our institutions' academic enterprise.

1 See John Cunningham, S.J., "The Study of Science in Catholic Higher Education in the United States: A Modern Nuisance?" Integritas 3.2 (Spring 2014).

David Quigley is provost and dean offaculties at Boston College, having previously served as dean of the College and Graduate School of Arts and Sciences. He is a professor of history, having taught a wide range of undergraduate and graduate courses on nineteenth-century United States and on political and urban history. His research to date has explored the history of race and democracy between the American Revolution and Reconstruction in local political cultures of New York. He is completing a new synthetic project, Last, Best Hope: International Lives of the American Civil War, and is editing both A Companion to American Urban History and Busing in Boston: A Brief History with Documents. 
This essay is a helpful conclusion to this weekend's discussions, not least in its insistent reminder of the central place of integration and wholeness in our tradition. Bill emphasizes "the importance of attending to the whole in Catholic higher education," and he makes an important linkage between that attention and the desire to educate our students toward wisdom. On our campuses, as we work to support our students' human flourishing, I don't think we spend enough time thinking about how central the sciences must be in the formation of a modern man or woman for others. To achieve a kind of wholeness, to construct a contemporary self of integrity, deep and sustained engagement with our scientific age seems increasingly essential. Meaningful experiences with experimentation, a sustained invitation to thinking scientificallythese should not be solely expected for our pre-med students and engineers, but should be our clear expectations for all our undergraduates.

Here I think of the students we welcome to Boston College each fall. Since I arrived in 1998, the number of entering students with a declared interest in majoring in STEM areas has doubled. Yet for all this increased interest in the natural sciences and mathematics, I'm struck more and more by our students' limited imagination of what it means to study in these fields and to live a life of consequences using their scientific training. At least at BC, to study science is, too often, imagined as a pathway toward medical school, and we confront serious problems of retention in our science majors once students come to terms with the fact that medical school might not be the appropriate path. It is imperative that we broaden our students' imaginings of science as major and as vocation.

Modeling, as we've been discussing, is absolutely essential here. Tom Plante made a strong case yesterday ${ }^{2}$ for the fundamental importance of "who John Cunningham is." Several of us reflected on the compelling example of how Marc Muskavitch teaches, and how he moves back and forth between biology and theology. ${ }^{3}$ I loved Bill's account of how Phon Hudkins alerted a younger Bill Mattison to the "points of contact" between fields, and helped cultivate in the younger scholar an understanding of his responsibility to attend to the various paths to truth and wisdom. Toward the end of the paper, Bill provides an account of "The Researcher as a Human Person," wonderfully evoking the kind of scientists we want at work in our universities. In reading that section, I thought of many conversations with science department chairs on our campus, and the eternal challenge of identifying the very best younger scientists who will thrive at our university and, in the process, will advance our mission. A few years back, the thenprovost and I urged the promotions committee and individual departments to explicitly account for mission in the promotions process. I was struck by the fact that both at the committee meeting and in the larger setting of the board of chairs, it was one of my science department chairs who was most helpful. He talked about the mentoring and

2 Thomas G. Plante, "Modeling Science and Faith Integration May Be More Powerful than Words," Integritas 3.2 (Spring 2014).

3 Marc A.T. Muskavitch, "Genetic Determinism in the Post-Genomic Age," Integritas 3.1 (Spring 2014). 
formation work that goes on in a natural science lab and helped our colleagues, and me, to get a better sense of how we can imagine the ways in which the researchers as human persons can make powerful contributions to the work of mission.

Two final points before I close, and open up to a broader and concluding conversation. The first relates to the relationship between disciplines on our campuses, and I find the gulf between fields is nowhere more vast than between the natural sciences and the liberal arts. Bill's essay offers up a few suggestive but not fully developed insights for thinking about the connections between disciplines. Early on, we learn that "Theology also deputizes and indeed is accountable to such inquiry." I'd like to learn more of how Bill understands this linkage, and the ways in which practitioners of different disciplines should engage with each other. I'm drawn to his account of scholars' responsibility to each other but I find myself wanting to read more on Bill's take on interdepartmental accountability. How might it work? How might we reveal this to our students? One of the frustrations of my own experience with curricular revision over the last couple of years at Boston College has been my encounter with the deep distrust that departments have for each other. In its most extreme cases, it can come across as interdepartmental contempt and animosity, but even in its milder form, I've found colleagues in individual departments looking down on the scholarship and rigor of entire other fields. Reaching back to the topic of our first roundtable in April 2013, I find Bill's argument for accountability between theology and the sciences compelling, but far from the reality on many campuses. Too often, the disciplines are left to float free on their own, accountable to no one but the standards of their own professional body.

To close, I would like to offer up not so much a comment as a couple of questions, issues that came to mind across all three papers but especially in my reflecting on Bill's eloquent one of a theologian's ongoing encounter with the scientific mind. I'd urge us all to reflect on these:

- What difference does it make that we're doing this kind of teaching and research in a Catholic university?

- How does the Catholic university become a different kind of place by more fully exploring the connections and tensions between the sciences and other disciplines? 